\title{
The Influence of the Acoustic Properties OF WOOD FOR THE PRODUCTION OF ELECTRIC SOLID BODY GUITARS
}

\author{
ZORIC, A. \& KALJUN, J.
}

Abstract: Musical instrument (electric solid body guitar) operates on the principle of mechanical vibration, which is transferred to the pick up that sends the signal to the amplifier that produces sound through the speakers (free space). For a good electric guitar sound, a good choice of pick-up and strings is not enough, but also the correct choice of materials for making the body and the neck, and of course the shape of both parts. The problem is in the acoustics of materials that have a decisive influence on the final sound image of a musical instrument. For the purpose of electric guitars production we researched the acoustic properties of the test subjects from Walnut wood (Juglans regia L.) and Ash wood (Fraxinus excelsior L.). At impulse transverse mechanical excitation we also determined the flexural rigidity and damping characteristics of the elements, and we set acoustic quality indicators.

Key words: wood, walnut, ash, acoustic properties, electric solid body guitar
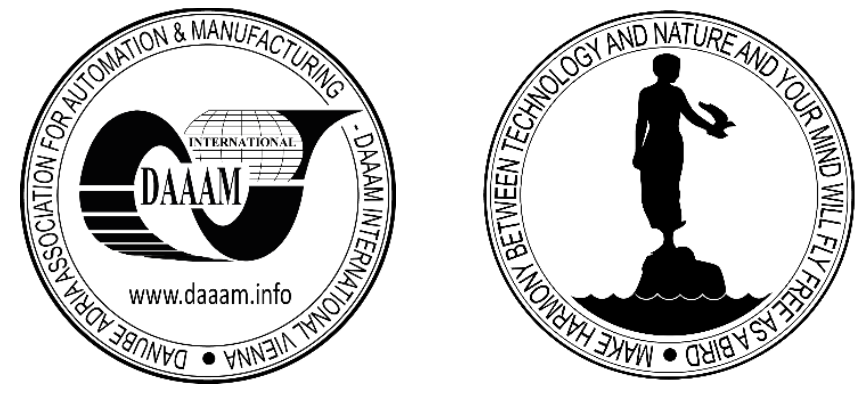

Authors' data: Zoric, A[nton], MSc*; Assistant professor Dr. Kaljun, J[asmin]*, * University of Maribor, Faculty of Mechanical Engineering, Smetanova street 17, 2000 Maribor, Slovenia, anton.zoric@student.um.si; jasmin.kaljun@um.si

This Publication has to be referred as: Zoric, A[nton] \& Kaljun, J[asmin] (2018). The Influence of the Acoustic Properties of Wood for the Production of Electric Solid Body Guitars, Chapter 18 in DAAAM International Scientific Book 2018, pp.195-210, B. Katalinic (Ed.), Published by DAAAM International, ISBN 978-3-902734-19-8, ISSN 1726-9687, Vienna, Austria DOI: 10.2507/daaam.scibook.2018.18 


\section{Introduction}

The function and effect of wood on electric solid body guitars is poorly understood. Most of the controversy is linked to some colour or to the sound itself. Opinions on this are very divided.Wood is a natural composite material. As a constituent material of music it plays an important role in the formation, and it contributes to their behavior and cultural identity.

There are several types of wood used for electric solid body guitars. In this field, not only acoustic aspect is important, but also the mechanical response, physical stability, visual aesthetics, and tactile properties which are very much needed. Due to very different sound characteristics of individual species there may be different types of electric solid body guitars manufactured from different types of wood.

Wood is used for production of various musical instruments due to indispensable physical and mechanical properties. The acoustic properties of wood species are largely defined by their anatomical and chemical structure in relation to homogeneity of the wood structure at macroscopic level. The wood anatomy affects porosity and hence density $(\rho)$ and rigidity of the wood, determined by the elastic modulus $(E)$. The ability to vibrate the wood structure is defined by a specific modulus of elasticity $(E / \rho)$ and by suppression of material vibrations $(\tan \delta)$ (Brémaud et al. 2012a). For example, for conifers it is clearly confirmed by the simultaneous fall in E/ $\rho$ and the increase in $\tan \delta$, with the increase in microfibrillation angle in the secondary layer of cell wall tracheid (Ono and Norimoto 1983), (Obataya, Ono, and Norimoto 2000). The viscous properties of wood are also significantly influenced by structure of the matrix of hemicellulose and lignin (Olsson and Salmkn 1997), (Ashby 2006), as well as the incrustation of extracts into cell walls (Brémaud et al. 2011).

The guitar strings and body of the electric solid body guitar represent a mechanically bound system. It is very reasonable to study modal base of the guitar solid body, position of the frequency conduction peak and modular damping of the propagation of conductivity.

It is also known that small differences in geometry or in angles can lead to large differences in vibrational behavior of the final product. In selection of materials we derived from selection of different types of wood, but comparative use of composite materials is not excluded.

For research work it is important to define the correlation of sound quality with physical properties of the electric solid body guitars, to describe the sound quality based on subjective assessments, and to predict the sound quality with a new design of electric solid body guitars.

C. Chiesa states that knowledge of the wood structure is very important for identifying materials used for musical construction of instruments (Chiesa et al., n.d.). Recent advances in musical acoustics have shown that mechanical properties of electric guitar solid body also affect the instrument's final sound. Assuming that excitation force is small enough to remain in linear approximation, the impulse response of the structure can be written as the sum of damped sinusoids. 
A. Pate and co-authors in their study point out that due to advances in musical acoustics, the mechanical properties of the hard body of electric guitars have influenced the final sound of the instrument (Fig. 1.) (Paté et al., n.d.).

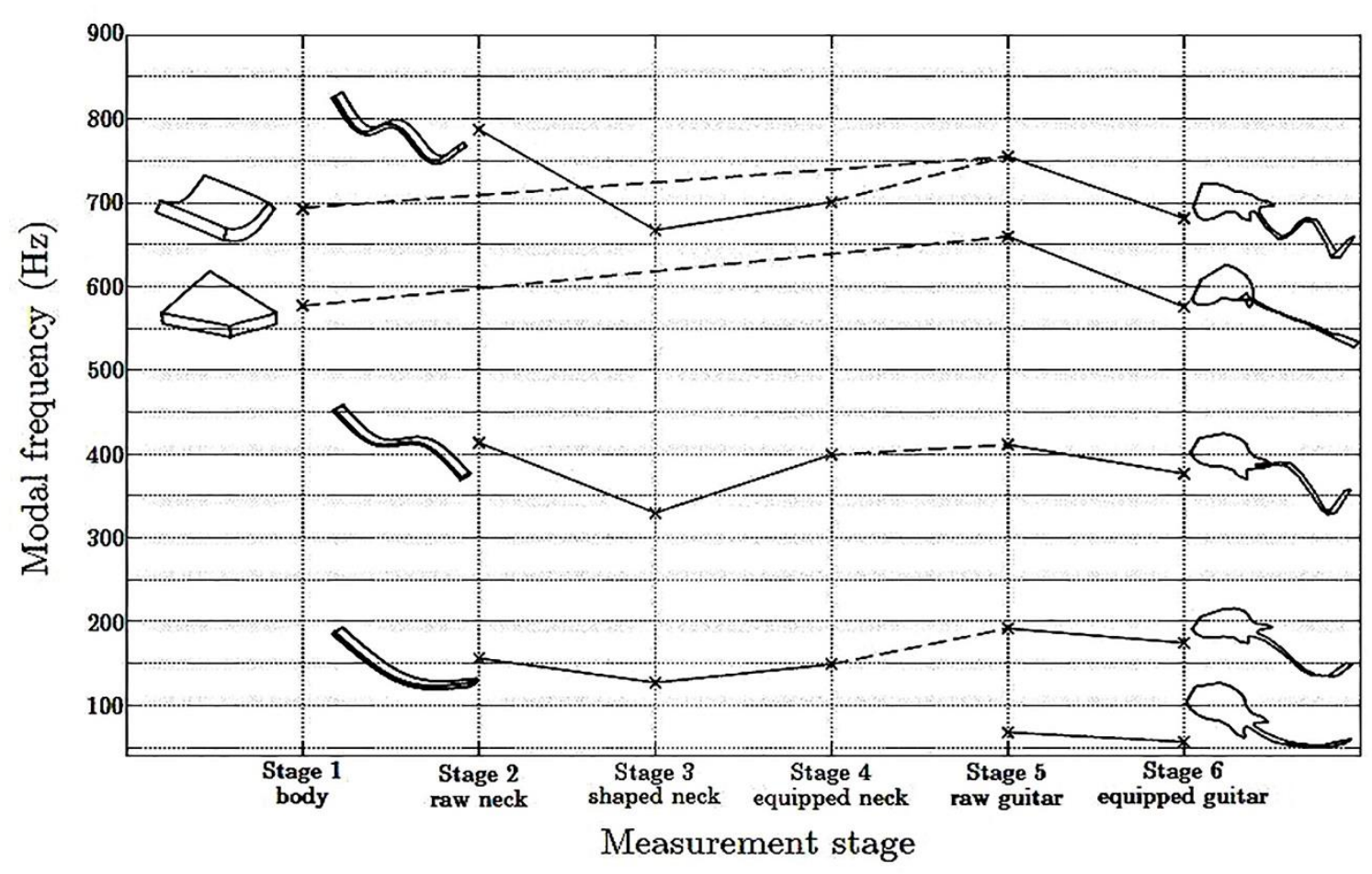

Fig. 1. Frequency and level of measurements

It is very important to measure the impulse response of the electric solid body guitar construction at the typical coupling points of the instrument, in order to study the sound of the instrument itself, so that precise measurement results can be obtained on the instrument (Paté et al. 2014). Wood fibers with a tubular structure can accumulate larger air volume in fibers than in cell walls. This fact has a great influence on the sound waves speed and the acoustic properties of a particular type of wood, as the study of J. Smardzewski shows (Smardzewski et al. 2014), which is very important for the production of musical instruments. T. Noguchi and co-authors in their study argue that these results coincide with empirical findings that sound quality is obtained through the wood aging, which is important in production of musical instruments (Noguchi, Obataya, and Ando 2012).

At present, an important aspect of research in acoustic instruments is to connect the measurable physical properties of the instrument with a subjective assessment of its sound quality or tone. The use of numerical models for determining the vibration modes that affect the desired musical tone is a valuable tool (Campos, Santos, and Paiva 2013). R. M. French in his study states that vibration strings may be the most fundamental element in understanding the behavior of the electric solid body guitar as a whole (French 2009). When a guitar string is plucked, there are two components of movement: rise and decay time. Fig. 2 shows (for E string) how the first 40 ms motion is increasing, followed by the decay. 
Zoric, A. \& Kaljun, J.: The Influence of the Acoustic Properties of Wood for the Pr...

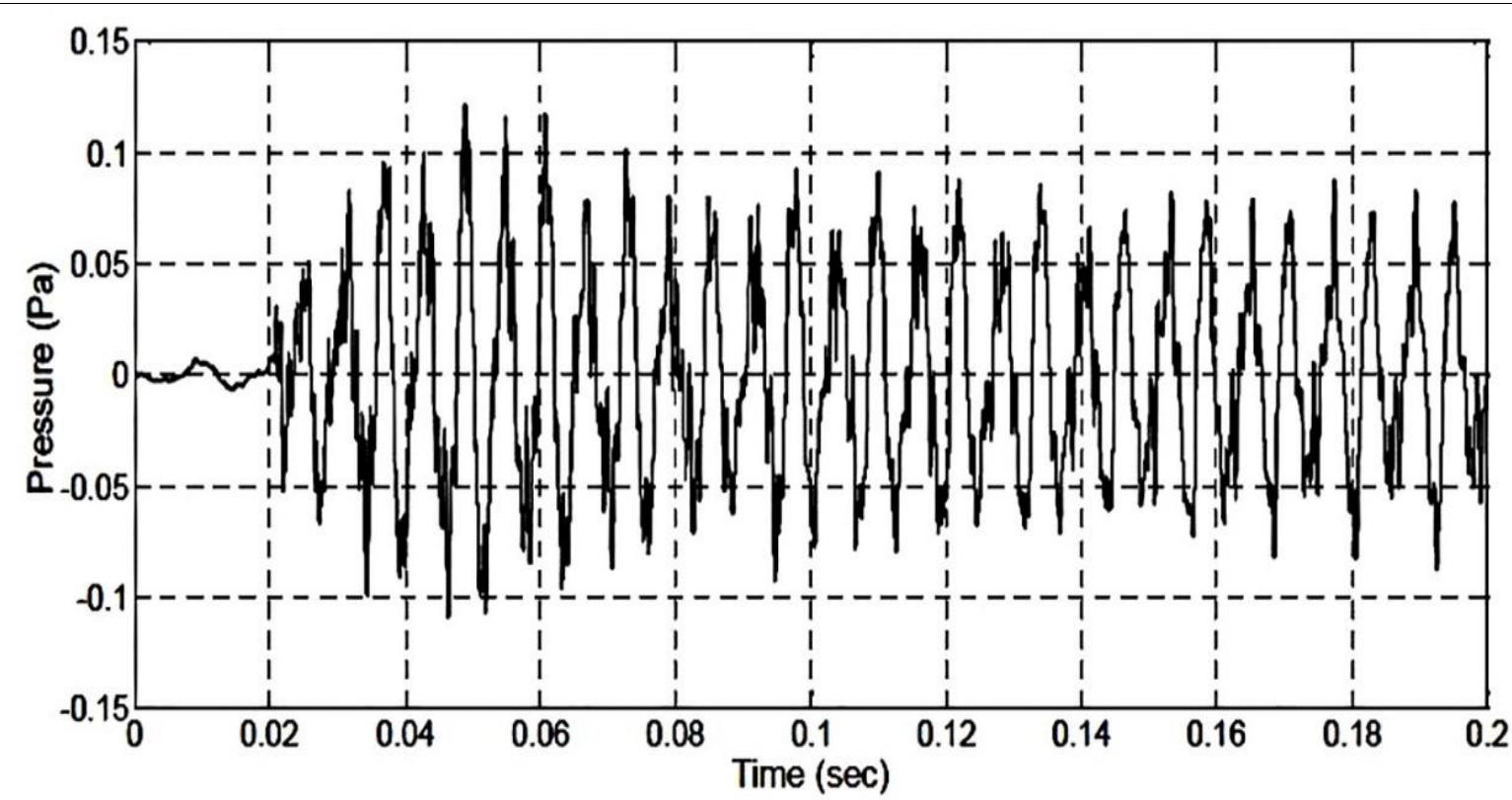

Fig. 2. Increase and Decline of the String E

Raimond Grimberg emphasizes that due to acoustic, aesthetic and process properties (feasibility, finishing), wood and wood-based cellulosic composites are the most appreciated materials for production of electric solid body guitars. Acoustic quality of the instrument shall be determined according to contribution of each element (shape, size, type of material used, characteristic of vibration of forces) (Curtu, Stanciu, and Grimberg 2008).

The aim of our research is to carry out an acoustic response and a modal analysis in free bending oscillation of a tester for the production of electric solid body guitars. With this kind of research, in parallel with the knowledge of elastomechanical material properties of the experimenter, we want to determine its acoustic quality and possibilities of using it in a electric solid body guitars.

\section{Experimental procedure}

\subsection{Material}

Two different materials were used to perform the measurements (Tab.1):

- Ash - year 1975 (origin from Bosnia in Herzegovina)

- Walnut - year 1978 (origin from Slovena)

\begin{tabular}{|l|l|l|l|l|}
\hline Material & Walnut & Ash & Walnut & Ash \\
\hline Lenght $[\mathrm{mm}]$ & 430 & 430 & 80 & 80 \\
\hline Width $[\mathrm{mm}]$ & 186 & 186 & 40 & 40 \\
\hline Height [mm] & 42.8 & 42.8 & 42,8 & 42,8 \\
\hline Mass [g] & 2133 & 2763 & 80 & 116,27 \\
\hline & & & & \\
Density $\left[\mathrm{kg} / \mathbf{m}^{\mathbf{3}}\right.$ ] & $\mathbf{6 2 3}$ & $\mathbf{8 0 7}$ & $\mathbf{6 2 3}$ & $\mathbf{8 0 7}$ \\
\hline
\end{tabular}

Tab. 1. Dimensions, mass and density of the wood in the tested specimens 


\subsection{Preparation of material}

From naturally dried and conditioned wood $\left(\mathrm{T}=20^{\circ} \mathrm{C}, \varphi=50 \%\right)$ we created elements $(\mathrm{n}=2)$ for production of electric solid body guitars. We selected longitudinally oriented elements of two domestic wood species, Ash (Fraxinus excelsior L.) and Walnut (Juglans regia L.).

The test pieces were $430 \mathrm{~mm}$ long, $186 \mathrm{~mm}$ wide, and $42.8 \mathrm{~mm}$ thick. In testers we cut out the recess for the pick-up and drilled the holes for bridge (Fig. 2-1). In parallel with the elements, we also produced smaller, more oriented testers $80 \times 40 \times 40 \mathrm{~mm}$ $(\mathrm{L}, \mathrm{R}, \mathrm{T} ; \mathrm{n}=2)$ (Tab. 1).

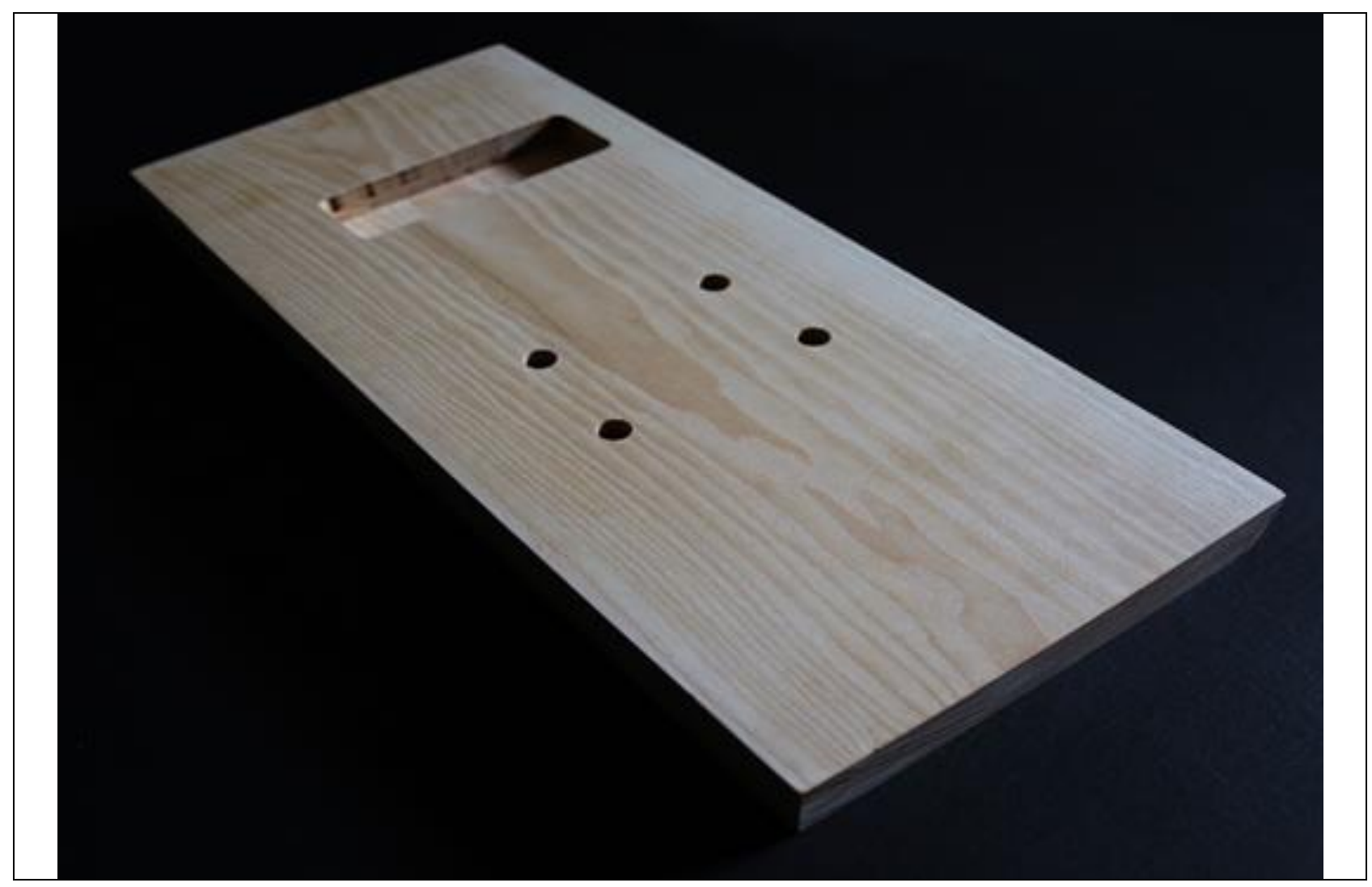

Fig. 3. Specimen

\section{Methods}

3.1 Determination of mechanical and acoustic properties in the frequency response of flexural bending and torsional oscillations

We used a measuring circuit with a condenser microphone (PCB-130D20), connected to PC via the NI-9234 measuring card to capture the signal (manufacturer National Instruments Ltd) to measure and record the sound signal.

All measurements were captured in time sound signal $(\mathrm{t}=3 \mathrm{~s})$ in 24 bit resolutions with 51200 samples per second, and further processed and analyzed in LabVIEW 8.0® (Fig. $4)$. 
Zoric, A. \& Kaljun, J.: The Influence of the Acoustic Properties of Wood for the Pr...

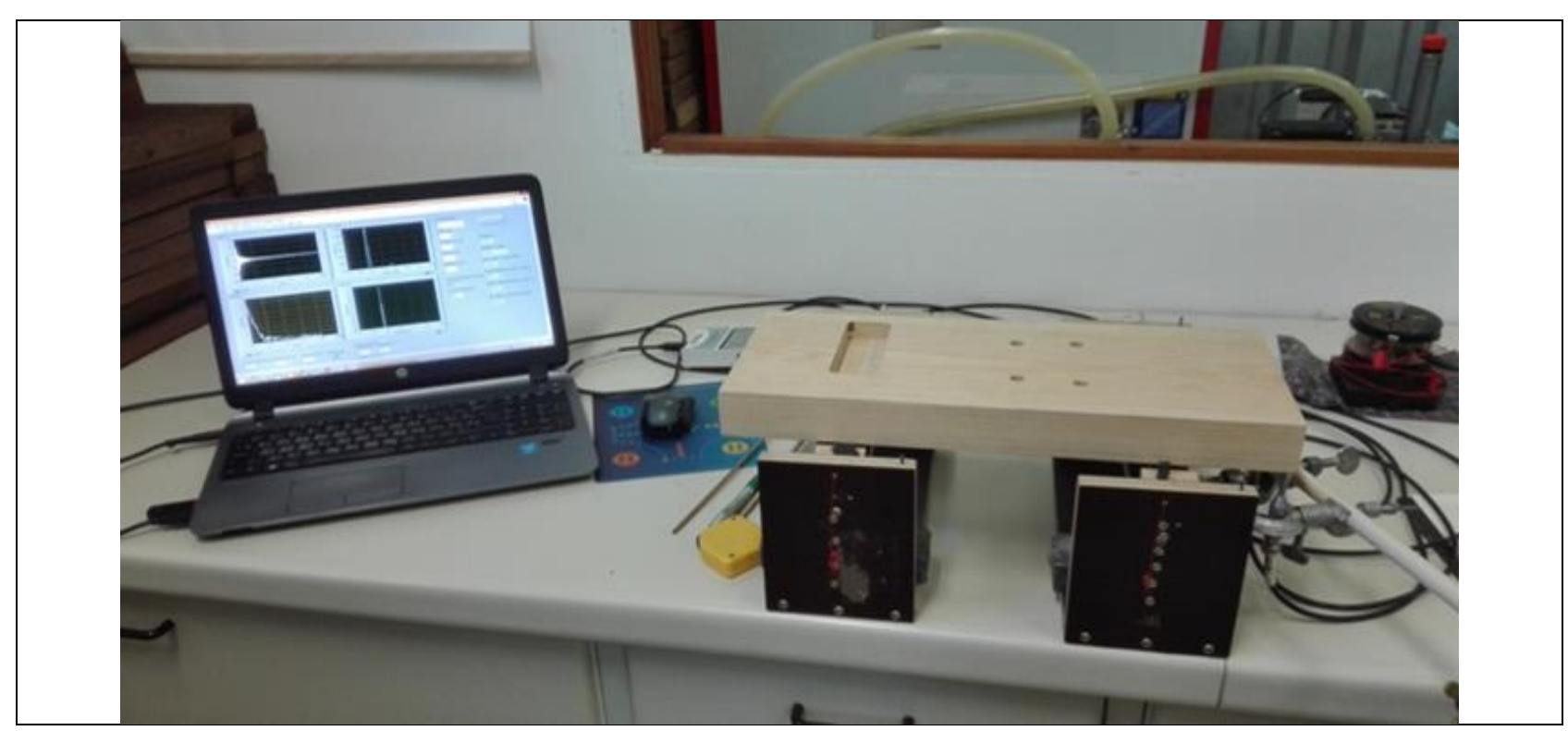

Fig. 4. Experimental set of free - free flexural vibration measurement of wood elements
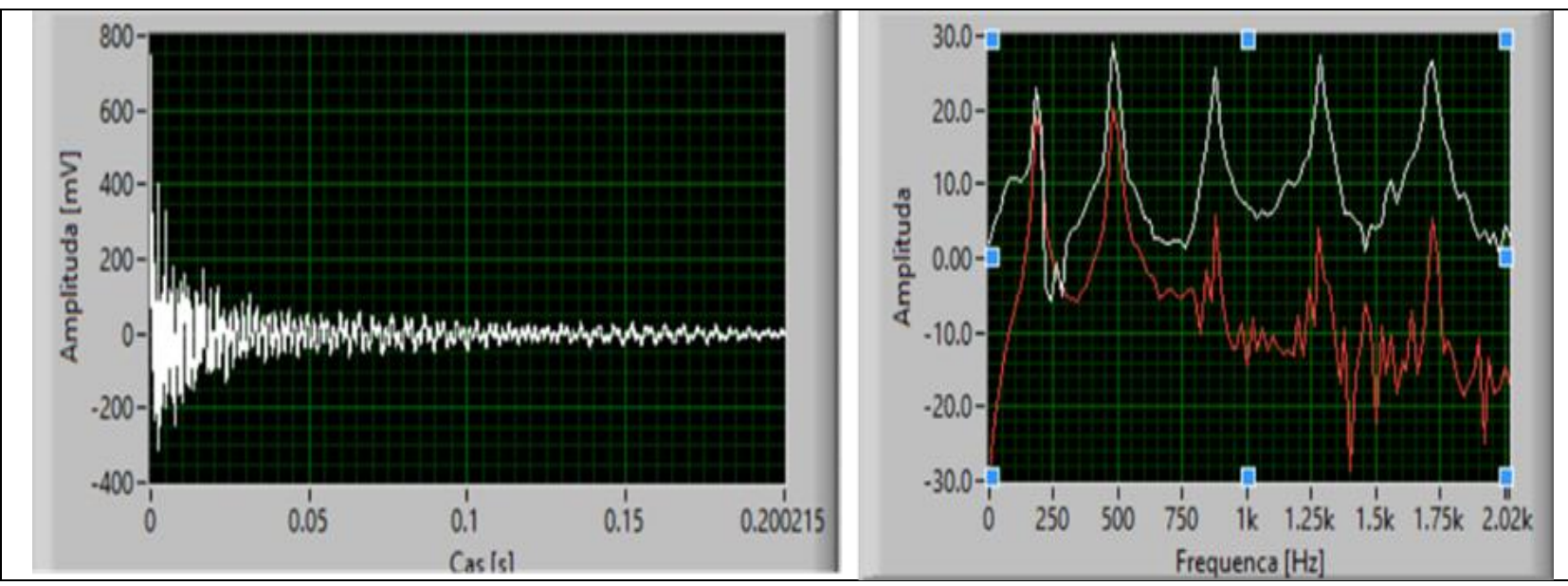

Fig. 5. Sound signal in time (left) and in the frequency range, with a frequency spectrum ( $\mathrm{t}>50 \mathrm{~ms}(-), 100<\mathrm{t}<150 \mathrm{~ms}(-)$ (right).

\subsection{Flexural mechanical excitation of specimens}

Longitudinally-radially oriented specimens were laid on two nylon elastic supports which were placed at the points of knots in the 1 st transverse oscillation mode ( $\mathrm{L}=$ $22.4 \%$ of the specimen length or $96,32 \mathrm{~mm}$ from edge of the specimen), and we pulled them impulsively mechanically and elastically into transverse bending fluctuations. The pulsed elastic excitation with rigid steel ball was performed in geometric axis on the open-end of the specimen, otherwise in geometric axis for the analysis of bending oscillation (Fig. 4). A condenser microphone PCB 130D20 was mirrored on the opposite arm of specimen. The sound signal was captured with measuring card NI9234, at frequency of $51 \mathrm{kHz}$ refresh rate. With Fast Fourier Transformation of the Signal (FFT), frequency response was determined in both excitation modes in the LabView programming environment (Fig.5).

To evaluate the flexural-bend fluctuations of the samples, we used Timoshenko's oscillation model (Eq.1), which also takes into account the shear stresses in specimen. 
To calculate the modulus of elasticity and shear modulus from Equation 1, we used Bordon's solution (Brancheriau and Bailleres 2002) which also takes into account the influence of blind pressure in the oscillation of the sample, but neglects the effect of the support (Eq 2) (Brancheriau and Bailleres 2002), (Hein et al. 2012).

$$
\begin{gathered}
E_{X} I_{G Z} \frac{\partial^{4} v}{\partial x^{4}}-\rho I_{G Z}\left(1+\frac{E_{X}}{K_{N} G_{X Y}}\right) \frac{\partial^{4} v}{\partial x^{2} \partial t^{2}}+\frac{\rho^{2} I_{G Z}}{K_{N} G_{X Y}} \frac{\partial^{4} v}{\partial t^{4}}+\rho A \frac{\partial^{2} v}{\partial t^{2}}=0 \\
\frac{E_{X}}{\rho}-\frac{E_{X}}{K_{N} G_{X Y}}\left[Q F_{2}(m) 4 \pi^{2} \frac{A L^{4}}{I_{G Z}} \frac{f_{n}^{2}}{P_{n}}\right]=4 \pi^{2} \frac{A L^{4}}{I_{G Z}} \frac{f_{n}^{2}}{P_{n}}\left[1+Q F_{1}(m)\right]
\end{gathered}
$$

In Equation 2, the parameters Q, F1, F2, $\mathrm{m}$ and $\Theta$ are calculated on the basis of the index (n), i.e. of each modal mode:

$$
\begin{aligned}
& Q=\frac{I_{G z}}{A L^{2}} \\
& F_{1}(m)=\theta^{2}(m)+6 \theta(m) \\
& F_{2}(m)=\theta^{2}(m)-2 \theta(m) \\
& \theta(m)=m \frac{\tan (m) \tanh (m)}{\tan (m)-\tanh (m)} \\
& m=\sqrt[4]{P_{n}}=(2 n+1) \frac{\pi}{2}, n \in N
\end{aligned}
$$

Parameters (Eq. 3 to Eq. 7) allow the linear regression model to be adjusted ( $Y_{n}=a+$ $\mathrm{b} \times \mathrm{X}_{\mathrm{n}}$ ) to the basic equation 2, where for each pulsating mode we calculate $X_{n}$ and $Y_{n}$ values (Eq. 8 and Eq. 9). The calculated initial value (a) of this model allows the calculation of the Timoshenko elasticity module $\left(\mathrm{E}_{\mathrm{X}}\right)(\mathrm{Eq} . .2$, Eq. 10), and from the slope of the model line (b), the shear module $\left(\mathrm{G}_{\mathrm{XY}}\right)$ is calculated (Eq. 11, Fig. 6).

$$
\begin{aligned}
& X_{n}=\left[Q F_{2}(m) 4 \pi^{2} \frac{A L^{4}}{I_{G Z}} \frac{f_{n}^{2}}{P_{n}}\right] \\
& Y_{n}=4 \pi^{2} \frac{A L^{4}}{I_{G z}} \frac{f_{n}^{2}}{P_{n}}\left[1+Q F_{1}(m)\right] \\
& E_{X}=a \times \rho \\
& G_{X Y}=\frac{E_{X}}{K \times b}
\end{aligned}
$$


Zoric, A. \& Kaljun, J.: The Influence of the Acoustic Properties of Wood for the Pr...

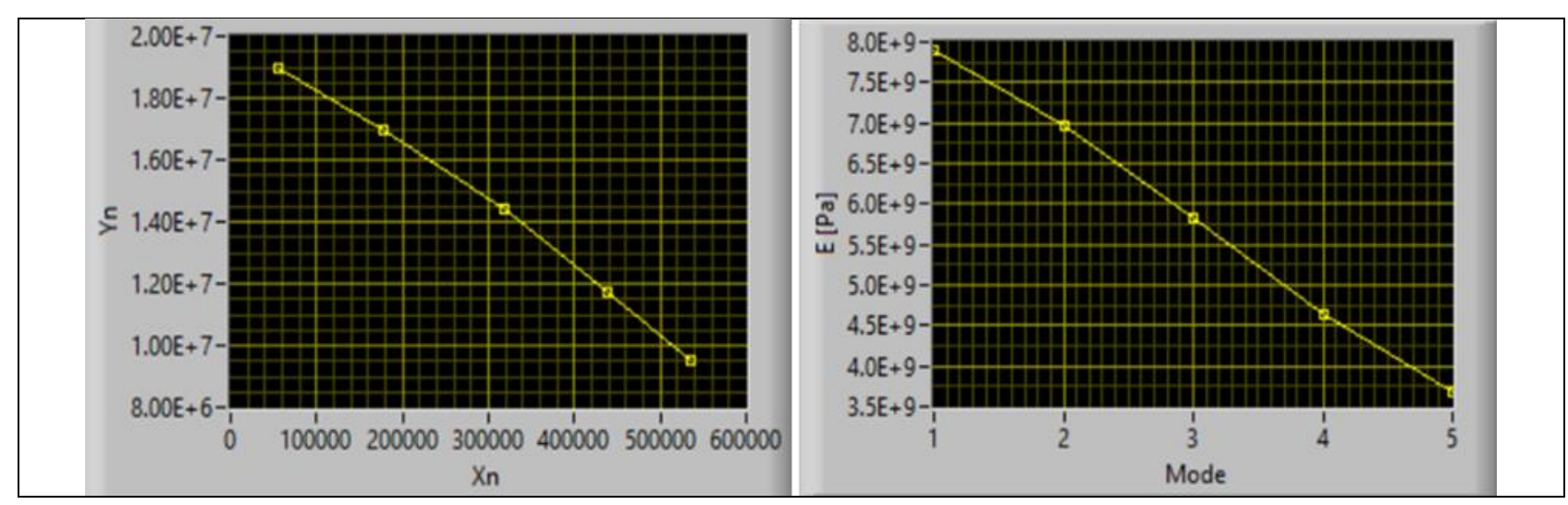

Fig. 6. Calculation of parameters by Bordonne's solution (Yn, Xn) (left) and the dependence of the modulus of elasticity from the vibrational mode $(1 \leq n \leq 5)$ (right).

Marks:

$E_{X}$ - bending modulus of elasticity [Pa],

$G_{X Y}$ - shear modulus [Pa],

$I_{G Z}$ - inertial moment of cross-section $\left[\mathrm{m}^{4}\right]$,

$f_{n}$ - the oscillation frequency of the sample in the i-th vibration mode,

$v$ - amplitude oscillations [m],

$t$-time [s],

$\rho$ - density $\left[\mathrm{kg} / \mathrm{m}^{3}\right]$,

$x$ - distance in the longitudinal direction of the test piece [m],

$A$ - cross-section $\left[\mathrm{m}^{2}\right]$,

$K_{N}$ - geometric constant $\left(\mathrm{K}_{\mathrm{N}}=5 / 6 \ldots\right.$ for rectangular cross-sections $)$,

$P_{n}$ - parameter to solve the Bernoulli constants (m), depends on the vibrational mode (n).

The Timoshenko modulus of elasticity $\left(E_{X}\right)$ achieves a higher value than the modulus of elasticity calculated from the simpler Bernoulli solution $\left(\mathrm{E}_{\mathrm{B}}\right)$. Bernoulli's solution is the basis for calculating the modulus of elasticity in the transverse oscillation of the sample (Eq.12). The equation is used for the base-as well as for higher vibration modes, where the calculated values of the modulus of elasticity decrease (Fig. 8).

$$
E_{B}=\frac{4 \times \pi^{2} \times L^{4} \times \rho \times f_{n}^{2} \times A}{I \times m_{i}^{4}}
$$

Marks:

$\mathrm{L}$ - length of the test piece [m],

$\rho$ - density $\left[\mathrm{kg} / \mathrm{m}^{3}\right]$,

$\mathrm{fn}$ - the frequency of the oscillation, where $\mathrm{n}$ represents a pulsating mode,

A - cross-section of the test piece $\left[\mathrm{m}^{2}\right]$,

I - the moment of inertia of the cross section $\left[\mathrm{m}^{4}\right]$ (rectangular cross section:

$\mathrm{I}=\mathrm{bh}^{3} / 12$, where $\mathrm{b}$ is the width and $\mathrm{h}$ of the workpiece height; and

$\mathrm{m}_{\mathrm{i}}$ - the correction coefficient (Eq.7), which depends on the vibrational mode (for the first vibration mode, $\mathrm{m}_{\mathrm{i}}=4.730$ ). 


\subsection{Acoustic indicators}

The damping of mechanical oscillation $(\tan \delta)(E q .17)$ of specimens was determined by measuring the logarithmic decimation.

With measured elastomechanical and damping characteristics of specimens (Eq.2), we also determined some important acoustic indicators for the evaluation of i.e. resonance wood.

The influence of differences in wood density on mechanical stiffness was excluded by specifying a specific modulus of elasticity $\mathrm{E}_{\mathrm{SP}}(\mathrm{Eq} .13)$ as well as acoustic coefficient K (Eq. 14). In addition we also determined Relative Acoustical Conversion Efficiency RACE (Eq. 16), which represents pure radiation of sound, looks at the degree of its damping and research Obataya (Obataya, Ono, and Norimoto 2000), and directly reflects the influence of material microstructure on sound radiation.

The specific elastic module $E_{\mathrm{sp}}[\mathrm{GPa}]$, where $\rho$ is the relative density of the wood ( $\rho_{\text {wood }}$ $\left./ \rho_{\text {water }}\right)$ :

$$
E_{s p}=\frac{E_{B}}{\rho}
$$

Acoustic coefficient $\mathrm{K}\left(\mathrm{m}^{4} \mathrm{~s}^{-1} \mathrm{~kg}^{-1}\right)$ :

$$
K=\sqrt{\frac{E_{B}}{\rho^{3}}}
$$

Acoustical Conversion Efficiency ACE $\left(m^{4} \mathrm{~s}^{-1} \mathrm{~kg}^{-1}\right)$ :

$$
A C E=\frac{K}{\tan \delta}
$$

RACE (Relative Acoustical Conversion Efficiency) was defined as an additional indicator, which is, like the specific modulus of elasticity $\mathrm{E}_{\mathrm{sp}}$ and $\tan \delta$, is independent of the wood density. Relative acoustic conversion efficiency RACE ( $\mathrm{km} / \mathrm{s})$ :

$$
R A C E=\frac{\sqrt{E_{s p}}}{\tan \delta}
$$

Sound attenuation coefficient $(\tan \delta)$ :

$$
\tan \delta=\frac{\alpha}{\pi f_{1}}
$$


Zoric, A. \& Kaljun, J.: The Influence of the Acoustic Properties of Wood for the Pr...

\section{Results and discussion}

\subsection{Physical properties of wood}

The examined specimens were in both cases longitudinally tangentially oriented, with Walnut wood also detecting a larger deviation of the fibers from longitudinal axis the specimen.

In walnut wood test the wood density was lower $\left(\rho_{\mathrm{u}}=623 \mathrm{~kg} / \mathrm{m}^{3}\right.$; Tab. 1) than average density for this wood species, which at $12 \%$ of wood moisture is $680 \mathrm{~kg} / \mathrm{m}^{3}$ In tested Ash wood, the specimen had a density of $807 \mathrm{~kg} / \mathrm{m}^{3}$, which is about $25 \%$ above average value for this species $\left(\rho_{\mathrm{u}}=690 \mathrm{~kg} / \mathrm{m}^{3}\right)(\mathrm{Kretschmann} 2010)$. Similarly, at slightly higher value than average, we also determined the speed of sound and modulus of elasticity.

The modulus of elasticity, determined from longitudinal and transverse oscillations of the test pieces, is similar, and in the case of solid wood the modulus in longitudinal oscillation was measured by $10 \%$ higher.

\subsection{Frequency response and acoustic indicators}

In frequency response of transversely excited free-standing specimens, the highest amplitudes were obtained for both types of wood in basic oscillation mode (Fig. 7).

The basic frequency (Tab.2) was $748 \mathrm{~Hz}$ for Walnut specimen, and in Ash specimen it was significantly higher $(\mathrm{f} 1=923 \mathrm{~Hz})$. By studying the 4th oscillation mode, we measured the own frequencies up to $3675 \mathrm{~Hz}$ in Walnut wood and up to $3573 \mathrm{~Hz}$ in Ash wood.

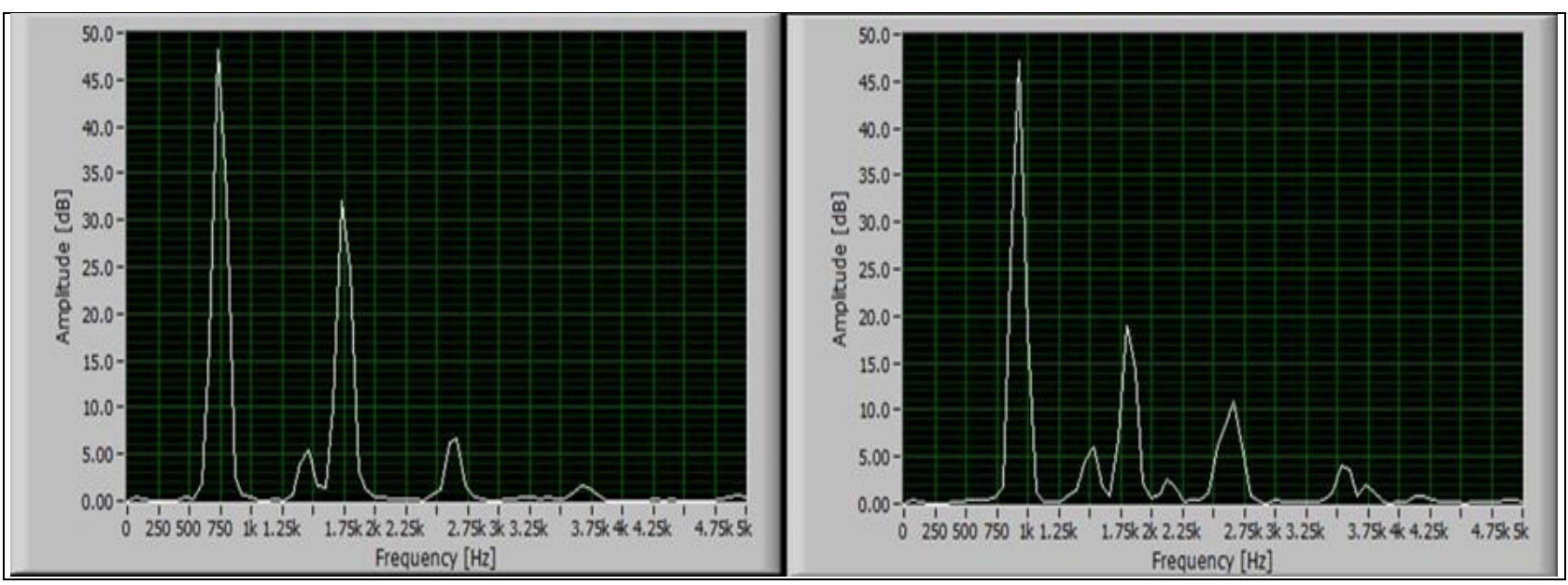

Fig. 7. Typical FFT spectrum of walnut- (left) and ash wood (right) elements for solid body of electric guitar after flexural excitation with present bending and torsion modal frequencies

The Timoshenko's mean modulus of elasticity was $8.8 \mathrm{GPa}$ in walnut and $16.6 \mathrm{GPa}$ in ash wood. The shear modulus $\left(\mathrm{G}_{\mathrm{XY}}\right)$ determined from Bordonne's solution by regression line (Eq. 2) was $0.42 \mathrm{GPa}$ and $0.46 \mathrm{GPa}$ for the walnut and ash wood respectively. The modulus of elasticity was reduced at higher vibration modes of tested specimens at both wood species, but more significant in ash wood (Fig. 8). 


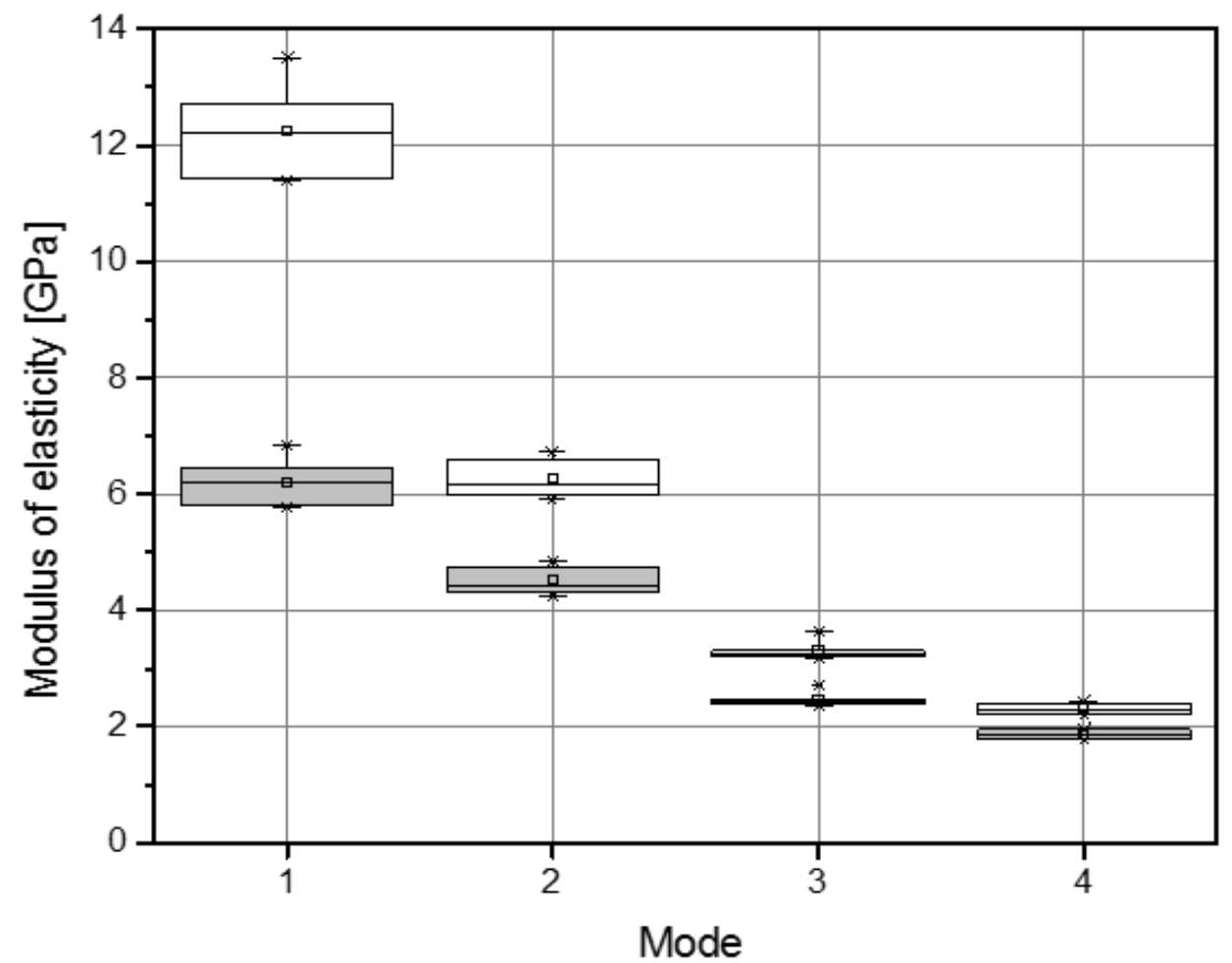

Fig. 8. Dependence of the modulus of elasticity (MOE) on vibration mode of walnut$(\square)$ and ash wood ( $\square$ ) elements for electric guitar solid body

The difference in the reduction of the modulus of elasticity with the increase of vibration mode (Fig. 6) is expected between wood species and is related to the difference in microstructure homogeneity of tested wood and to the difference in shear stiffness.

One of the reasons for lower shear modulus and shear stress determined from flexural vibration is due reduction of cross section of tested elements by routing of standard pickup hole (Fig. 1). The second reason is related to the measuring method, since similar differences are also found by other studies (Bucur 2006);(Divós and Tanaka2005).

The differences in some indicators of acoustic quality, i.e. acoustic coefficient $\mathrm{K}$ and in acoustic conversion efficiency ACE were between the tested wood species negligible. Values were quite low and similar to results in other studies (Tab. 2) (Bucur 2006); (Brémaud et al. 2012b); (Straže A., Mitkovski B., Tippner J., Čufar K. 2015).

Significantly greater value was confirmed in ash wood for RACE, which neutralizes the difference in density in the studied samples (Obataya, Ono, and Norimoto 2000), and proposes that radiation of sound energy is somewhat better in ash wood. 
Zoric, A. \& Kaljun, J.: The Influence of the Acoustic Properties of Wood for the Pr...

\begin{tabular}{|l|l|l|}
\hline Indicator $\backslash$ Material & walnut & ash \\
\hline $\mathrm{f}_{1}\left[\mathrm{~s}^{-1}\right]$ & 748 & 923 \\
\hline $\tan \delta[]$ & 0.011 & 0.008 \\
\hline $\mathrm{E} / \mathrm{\rho}[\mathrm{GPa}]$ & 9.79 & 14.93 \\
\hline $\mathrm{K}\left[\mathrm{m}^{4} \mathrm{~s}^{-1} \mathrm{~kg}^{-1}\right]$ & 5.04 & 4.81 \\
\hline $\mathrm{ACE}\left[\mathrm{m}^{4} \mathrm{~s}^{-1} \mathrm{~kg}^{-1}\right]$ & 246 & 261.0 \\
\hline RACE $\left[\mathrm{km} \mathrm{s}^{-1}\right]$ & 153 & 209.0 \\
\hline
\end{tabular}

Tab. 2. Mean acoustic quality indicators of walnut and ash, determined by flexural frequency response of elements electric guitar solid body

We confirmed in addition the increase in vibration damping at higher vibration modes of both tested wood species (Fig. 9). In the fundamental vibration mode, a slightly smaller damping was confirmed for ash wood $(\tan \delta=0.008)$ compared to the damping in walnut $(\tan \delta=0.011)$. In the case of higher vibration modes this difference is reduced, whereas walnut is proven to be a less damped material comparing to ash wood.

Smaller vibration damping of walnut at higher modes and frequencies than in ash wood, related with its significantly lower density, could positively impact on vibrating of future built solid body of electric guitar. It can be expected in this case higher energy transfer at similar string playing frequency and a structure resonance of the electric solid body guitar. In this respect the alteration of resonance of corresponding strings and of timbre effects is expected, followed by reduced decay time, as was confirmed in related studies (Fleischer 1998); (Pat et al. 2014).

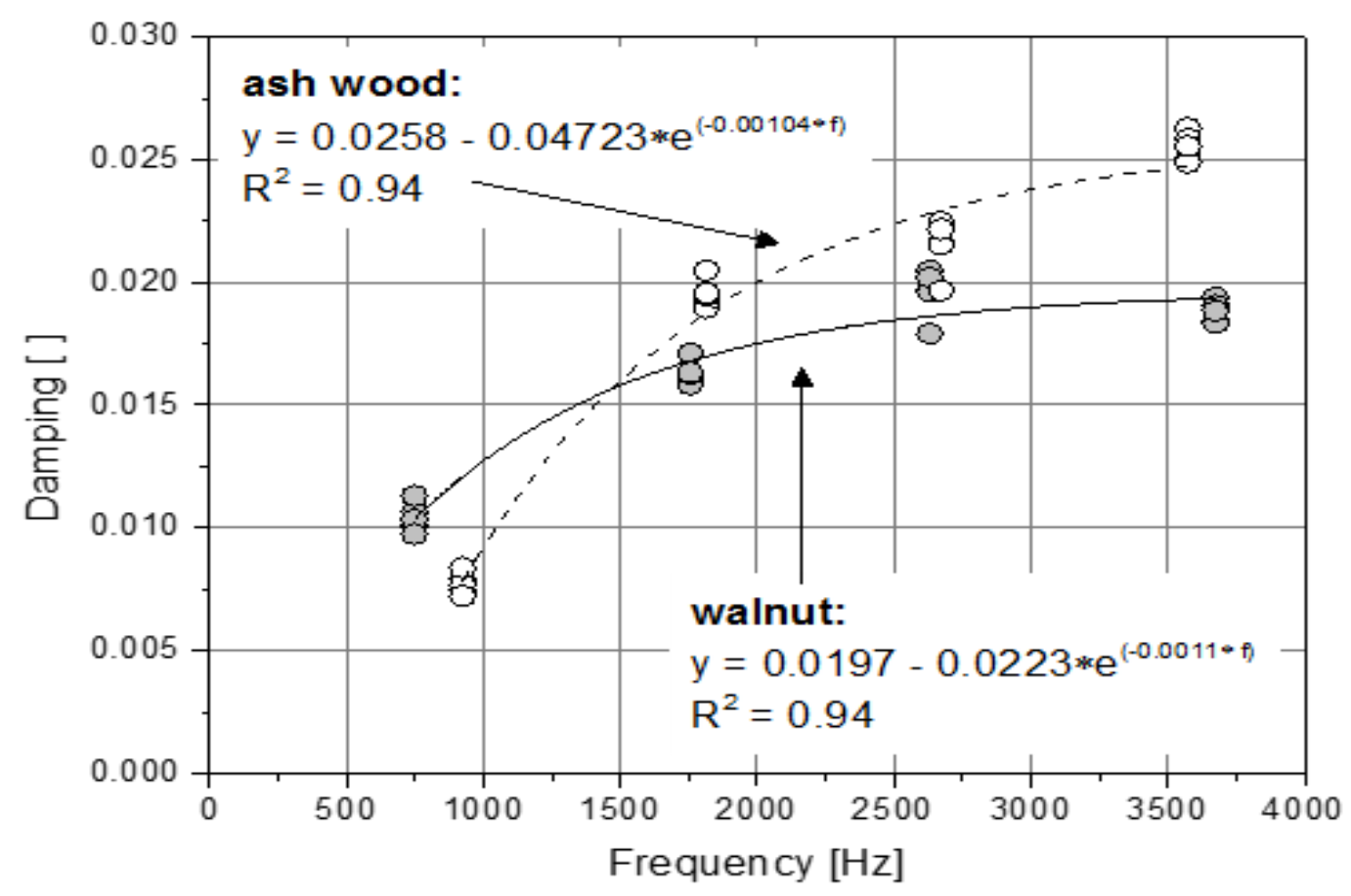

Fig. 9. The dependence of vibration damping on vibration mode frequency of walnutand ash wood elements for electric solid body guitar 


\section{Further work}

In the continuation of our research, we intend to define the user method (protocol) (Fig. 10), through which we can perform laboratory measurements of vibration accuracies, and by using this method we determine the acoustic response of the material for making the instrument (electric solid body guitar), thus ensuring a high quality sound instruments using various materials, such as those incorporated in the original instrument.

The next step is to determine the influence of shape and construction on the acoustics of the instrument, and then to set up a methodology for the development of a musical instrument with the corresponding construction and design recommendations and verification of the methodology (Fig. 11).

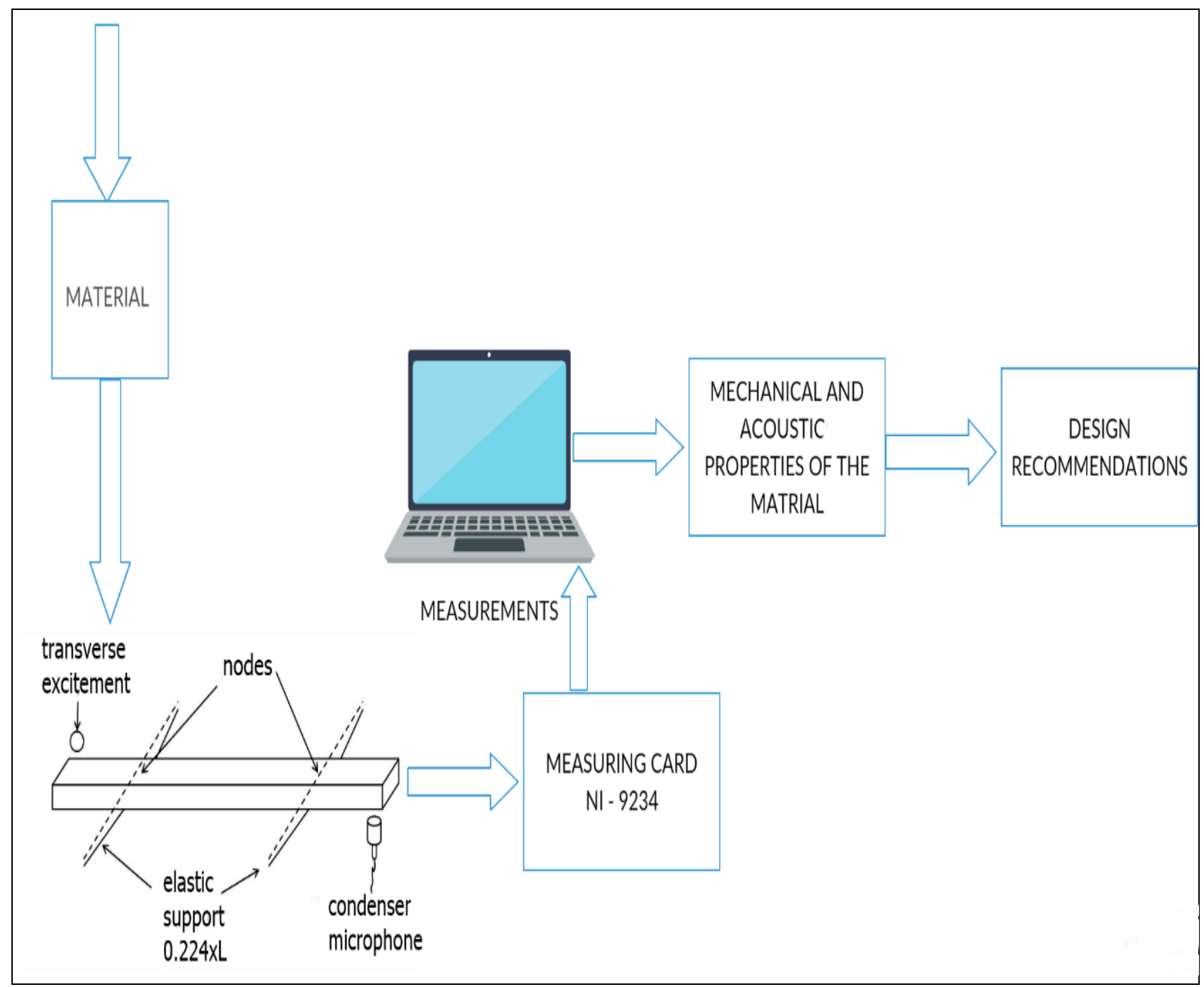

Fig. 10. Measurement protocol 
Zoric, A. \& Kaljun, J.: The Influence of the Acoustic Properties of Wood for the Pr...

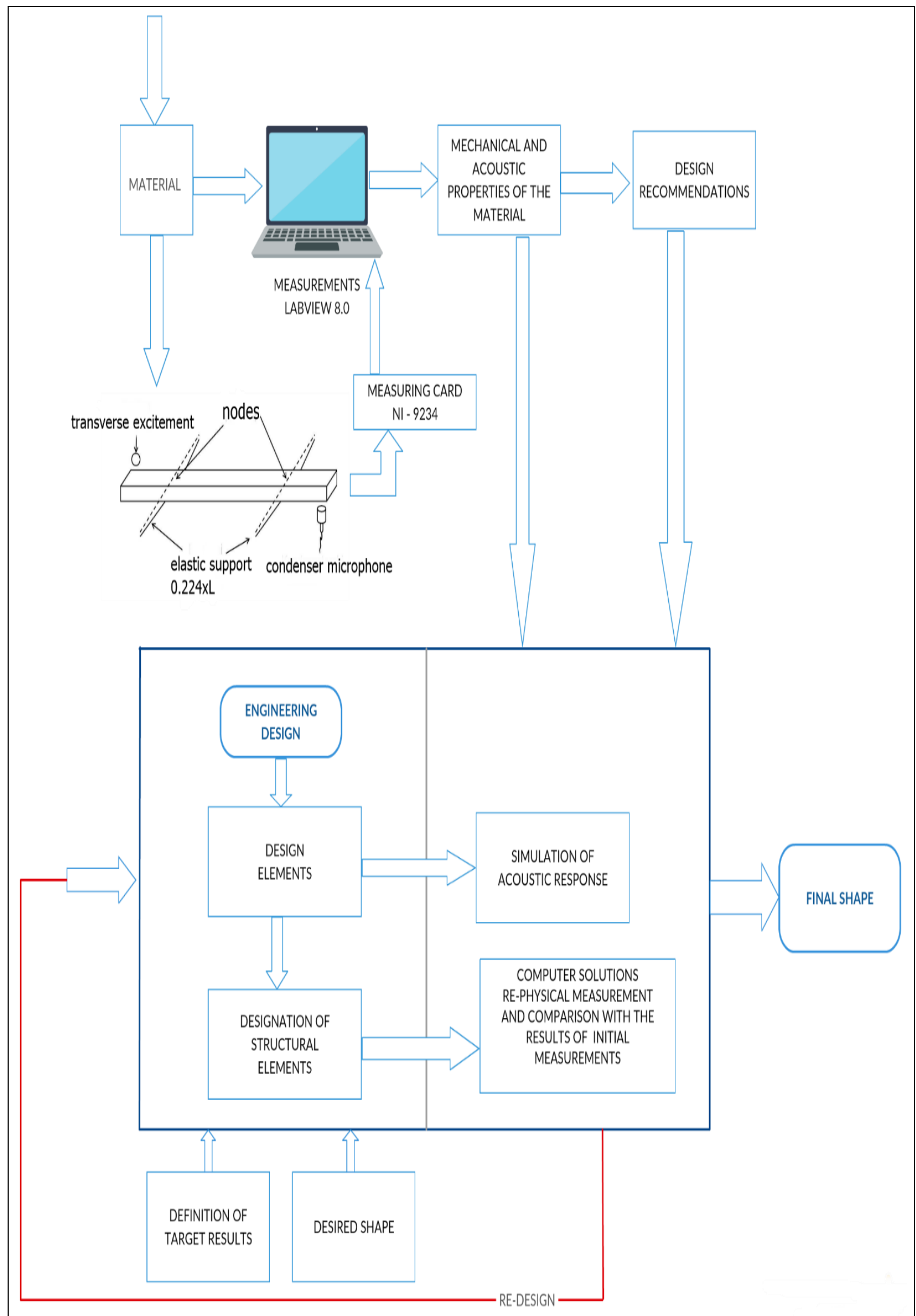

Fig. 11. Methodology of the development of a musical instrument - electric guitar 


\section{Conclusions}

To sum up, the authors can despite great variability of wood statistically prove differences in acoustic and mechanical properties of tested two hardwood species, i.e. walnut and ash wood, for use in making of electric solid body guitars. The research confirmed the better mechanical properties of ash wood, that is, the larger modulus of elasticity and shear modules in all anatomical directions and planes. At the same time, some indicators of acoustic quality were better in ash wood, but only in the basic vibration mode.

It has also proved to be less homogeneous and, consequently, poses great differences between vibrating modes. The results will further be used in the study of laboratory and numerical model of electric solid body guitar. The impact of the model geometry and used material will be tested to check the string/structure mechanical coupling and possible effect on vibration characteristics of the electric solid body guitar.

\section{References}

Ashby, Michael F. 2006. "Engineering Materials 2," 352.

Brancheriau, L., and H. Bailleres. 2002. "Natural Vibration Analysis of Clear Wooden Beams: A Theoretical Review." Wood Science and Technology, no. 36: 347-65. doi:10.1007/s00226-002-0143-7.

Brémaud, Iris, Nadine Amusant, Kazuya Minato, Joseph Gril, and Bernard Thibaut. 2011. "Effect of Extractives on Vibrational Properties of African Padauk (Pterocarpus Soyauxii Taub.)." Wood Science and Technology, 735-45. doi:10.1007/s00226-0100337-3.

Brémaud, Iris, Yves El Kaïm, Daniel Guibal, Kazuya Minato, Bernard Thibaut, and Joseph Gril. 2012a. "Characterisation and Categorisation of the Diversity in Viscoelastic Vibrational Properties between 98 Wood Types." Annals of Forest Science, no. 35: 735-54. doi:10.1007/s13595-011-0166-z.

- 2012b. "Characterisation and Categorisation of the Diversity in Viscoelastic Vibrational Properties between 98 Wood Types." Annals of Forest Science 69: 37386. doi:10.1007/s13595-011-0166-z.

Bucur, V. 2006. Acoustics of Wood. Berlin, Springer Verlag. Vol. 393. doi:10.4028/www.scientific.net/MSF.210-213.101.

Campos, José Maria, Dos Santos, and Guilherme Orelli Paiva. 2013. "Vibroacoustic Numerical Analisys of a Brazilian Guitar Resonance Box."

Chiesa, Carlo, Bruce Carlson, Catherine Lavier, Xavier Guerland, Ulrich Leisinger, Laria Bonaduce, Susanna Bracci, et al. n.d. "Multidisciplinary Approach to Wooden Musical Instrument Identification.”

Curtu, I, M D Stanciu, and R Grimberg. 2008. "Correlations between the Plates' Vibrations from the Guitar's Structure and the Physical, Mechanical and Elastically Characteristics of the Composite Materials." Amta '08: Proceedings of the 9th Wseas International Conference on Acoustics \& Music: Theory \& Applications, 55-60\r144. 
Divós, Ferenc, and Toshinari Tanaka. 2005. "Relation between Static and Dynamic Modulus of Elasticity of Wood." Acta Silvatica \& Lignaria Hungarica 1 (February): 105-10. http://agris.fao.org/agris-search/search.do?recordID=DJ2012077853.

Fleischer, Helmut. 1998. "Mechanical Vibrations of Electric Guitars." Acta Acustica United with Acustica 84 (January): 758-65.

French, Richard Mark. 2009. Engineering the Guitar. doi:10.1007/978-0-387-743691 .

Hein, Paulo Ricardo Gherardi, Josá Tarcísio Lima, Joseph Gril, Antônio Marcos Rosado, and Loïc Brancheriau. 2012. "Resonance of Scantlings Indicates the Stiffness Even of Small Specimens of Eucalyptus from Plantations." Wood Science and Technology 46 (4): 621-35. doi:10.1007/s00226-011-0431-1.

Kretschmann, David E. 2010. "Chapter 5 - Mechanical Properties of Wood." Wood Handbook - Wood as an Engineering Material, 1-46. http://www.fpl.fs.fed.us/documnts/fplgtr/fplgtr190/chapter_05.pdf?

Noguchi, Takunori, Eiichi Obataya, and Kosei Ando. 2012. "Effects of Aging on the Vibrational Properties of Wood." Journal of Cultural Heritage 13: S21-25. doi:10.1016/j.culher.2012.02.008.

Obataya, E., T. Ono, and M. Norimoto. 2000. "Vibrational Properties of Wood along the Grain." Journal of Materials Science, no. 35: 2993-3001. doi:10.1023/A:1004782827844.

Olsson, Anne-Mari, and Lennart Salmkn. 1997. "The Effect of Lignin Composition on the Viscoelastic Properties of Wood." Nordic Pulp and Paper Resource Journal, no. 3: 140-44.

https://www.researchgate.net/profile/Lennart_Salmen/publication/263948942_The_ef fect_of_lignin_structure_on_the_viscoelastic_properties_of_wood/links/568a3d6608 aebccc4e19e370/The-effect-of-lignin-structure-on-the-viscoelastic-properties-ofwood.pdf.

Ono, Teruaki, and Misato Norimoto. 1983. "Study on Young's Modulus and Internal Friction of Wood in Relation to the Evaluation of Wood for Musical Instruments." Japanese Journal of Applied Physics, no. 22: 611-14. doi:10.1143/JJAP.22.611.

Pate, Arthur, Jean-Lo€ Ic, Le Carrou, and Beno ${ }^{\wedge}$ It Fabre. 2014. "Predicting the Decay Time of Solid Body Electric Guitar Tones." Acoustical Society of America, 3045-55. doi:10.1121/1.4871360.

Paté, A, J.-L Le Carrou, F Teissier, and B Fabre. 2014 "Monitoring of the Making Process of a Handcrafted Electric Guitar.". Proceedings of International Symposium in Musical Acoustics, Le Mans, France, 301-6.

Smardzewski, Jerzy, Wojciech Batko, Tadeusz Kamisiński, Artur Flach, Artur Pilch, Dorota Dziurka, Radosław Mirski, Edward Roszyk, and Adam Majewski. 2014. "Experimental Study of Wood Acoustic Absorption Characteristics." Holzforschung 68 (4): 467-76. doi:10.1515/hf-2013-0160.

Straže A., Mitkovski B., Tippner J., Čufar K., Gorišek Ž. 2015. "Structural and Acoustic Properties of African Padouk (Pterocarpus Soyauxii) Wood for Xylophones." European Journal for Wood and Wood Products, 77, 2: 235. 